\title{
Use of Social Networking Sites Among the Student of Universities in Bangladesh: A Case Study of Cumilla District
}

\author{
Dr. Md. Ruhul Amin \\ Associate Professor \\ Department of Public Administration \\ Comilla University, Bangladesh-3506 \\ E-mail: rubelcou@gmail.com
}

Md. Rashidul Islam Sheikh (Corresponding author)

Associate Professor

Department of Public Administration

Comilla University, Bangladesh-3506

E-mail: mrisheikh@cou.ac.bd,mrisheikh@yahoo.com

Received: May 5, $2021 \quad$ Accepted: May 31, $2021 \quad$ Published: June 14, 2021 


\section{Abstract}

Social networking sites are a well-known word in today's world because of their enormous growth, development, and utilization. It has created a new world without boundaries. The total population, 5 percent, 9 percent, 10 percent, 38 percent, and 78 percent of Bangladesh, Pakistan, India, China, and the USA using the internet reported by the World Bank (Editor, 2013). Teenagers and young adults are used social networking sites devotedly - the study conducted on four universities in Cumilla district, Bangladesh. This research aims to determine the causes and consequences of using social networking sites (SNSs) among the students at universities in Cumilla, Bangladesh. In this study, we have used the survey method and questionnaire tools for collecting the data. The information was collected from 200 students through purposive sampling. We have assessed and analyzed the data through descriptive statistical methods. Some significant findings of the study demonstrate that the students use the SNSs to communicate with friends and family, collecting educational information. They spend an average of $2 / 3$ hours daily using SNSs. Among the SNSs, Facebook is the most popular site. Findings also revealed that the excessive use of SNSs creates physical and mental disorders.

Keywords: Internet, Social networking sites, Students, Public-Private University, Bangladesh

\section{Introduction}

Technology becomes an integral part of life in the modern age, especially social networking sites becoming a prominent part of many young people's lives. In the last couple of years, we have faced a new phenomenon called social networking sites interacting with other users who have a common interest. It is like an illusion of SNSs mania among young people (Meena et al., 2012). Social networking sites have tremendous growth and popularity around the world. Teenagers and young adults are the most active users of SNSs. Maximum time SNSs are used to communicating with nears and dears through the social networking sights sharing their views, discussions on important topics, information, etc., are the most common topics on SNSs. According to the various research work on this area worldwide, it has a significant impact on the lives of the young generation. The widespread SNSs phenomenon has emerged over the last ten to fifteen years. Within this period, it becomes more popular than others. More than ten million internet users use SNSs both in their leisure time or working time. There is no doubt that SNSs provides many opportunities to young students like employment opportunities, marketing job, personal growth, and sharing of information and News, but the opposing sides are that the ill motives people involved in online predators. One can quickly enter the SNSs. However, it is challenging to find a way out of these entire SNSs (P. J. Aliyas et al., 2012). These sites give us many personal, social, and countrywide development opportunities. It creates a platform for many cybercrimes. Online SNSs like Facebook, Twitter, Linked In, Viber, WhatsApp, IMO, Skype, YouTube, etc., are the famous sites used in Bangladesh.

Throughout the country, young people were logging, creating profiles, updating information, and writing extensive comments back and forth. We have found tremendous competition among 
young adults to become famous people in the virtual arena. In this study, we have tried to determine the impact of SNSs on the students in tertiary level education in Bangladesh. This paper also tried to explore the scenario of whether SNSs are advantageous or disadvantageous for students.

The general objective of this study is to find out the impact of SNSs on the students at universities in Bangladesh. The specific objectives are as follows:

$>$ To identify how social networking sites affect students' academic performance,

$>$ To find out why the students randomly use social networking sites and,

$>$ To identify the positive as well as negative impact on students.

\section{Literature Review}

Social networking site is a community of people that relate to a specific target/goal. SNSs are online communities that allow users to communicate and share photographs, messages, music, and other types of information (Bristy, 2016). During the Cold War period, the USA tried hard to find out a new communication medium to communicate with their troops and security experts who were working outside of the country, without the use of the telegraph, telephone, or fax. Finally, they discovered the internet in the cold war period. Gradually, rich Asian countries and other parts of the world got access to it. Importantly, it was available in Bangladesh after the few years of its invention. Internet facilities were introduced in Bangladesh in 1996. After launching the Internet, National poll results were available to the citizens by using World Wide Web. National poll results were the first-ever usage event in Bangladesh. This attempt was highly cherished worldwide, especially for the Bangladeshis who are living outside of the county.

Gradually, Bangladeshi general peoples started diverse use of the internet. However, large numbers of the population still do not have access to the internet till now. Nowadays, internet users are mainly using social networking sites rather than other applications or sites. In recent years, social networking sites have been the most popular online destinations (Sultana, 2017). The people of our county mostly use social networking sites, such as Facebook, Twitter, Viber, Imo Skype, etc. Information flows quickly pass-through Facebook and other social sites. Sometimes it has a remarkable impact on the people of our county. In Bangladesh, 99,5560 people are involved with the internet, and about 83 percent of them are involved with social networking sites (SNSs). A vast and active community is involved with the different Social Media.

At present, SNSs have the significant influence of our regular lives, and it helps in every step of our daily life, such as political-economic and educational. It plays a vital role in the decision-making of social, economic, political, and educational sectors (Hosain Shahid Shohrowardhy, 2012). The remarkable growth of SNS in Bangladesh is 2 percent or around 5 million people each year. Still, the general peoples of Bangladesh are not familiar with social 
networking sites due to inadequate income activities. There is a leading and dominant age group (18-24) in Bangladesh in the user pool of the social networking arena (HM, 2017).

\section{Research Method and Materials}

For conducting this study, relevant data/information was collected from both primary and secondary sources. For primary sources, data was collected through a well-defined questionnaire and interview method. The questionnaire was semi-structured and open-ended for the collection of data. The required information and data were collected from undergraduate and graduate-level students. In secondary sources- various books, journals, articles, newspapers were used. Descriptive statistical tools like percentages, tables, pie charts, and diagrams were used to analyze the data generated from the respondents (M. Aminuzzaman Saluddin, 1998).

\subsection{Geographical Location of the Research Area}

In this research, four Universities (one public and the rest three were private universities) were selected based on academic atmosphere, quality education, the number of students, students' socio-economic backgrounds, etc. The Universities were: Comilla University (public), and private universities were CCN University of Science and Technology, Britannia University, and Bangladesh Army International University of Science and Technology. This research has 200 respondents from the population as a purposive sampling where 50 students from each University, respectively. The geographical location of the research is the Cumilla district in Bangladesh which is shown by the following map.

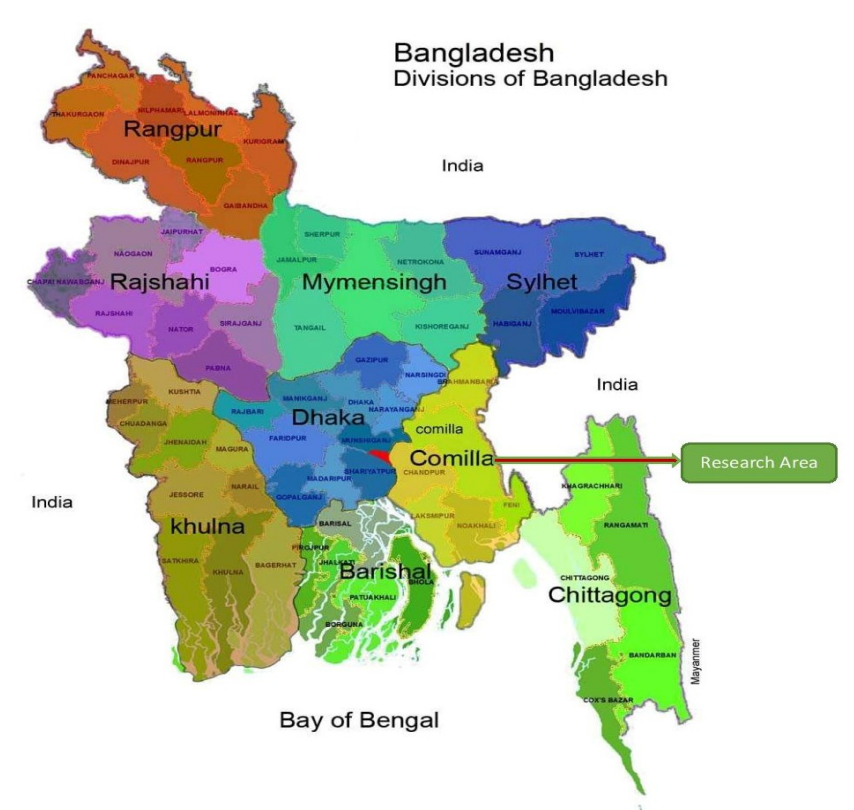

The research area is selected due to the convenience of data collection and comparatively easy 
communication with the respondents. Due to the shortage of funds and time constraints and especially in the Covid-19 pandemic, we have chosen the specific area of Bangladesh. In addition, both of us are familiar with the selected research area.

\section{Findings and Analysis}

\subsection{Gender}

Table 1. Gender Profile of Respondents

\begin{tabular}{|c|c|c|c|c|}
\hline \multirow[b]{2}{*}{ S.L } & \multirow[b]{2}{*}{ Name of the Institutions } & \multicolumn{2}{|l|}{ Gender } & \multirow{2}{*}{$\begin{array}{l}\text { Total } \\
\text { Students }\end{array}$} \\
\hline & & $\begin{array}{l}\text { No. of Male } \\
\text { Students }\end{array}$ & $\begin{array}{l}\text { No. of Female } \\
\text { Students }\end{array}$ & \\
\hline 1 & Comilla University & 25 & 25 & 50 \\
\hline 2 & Britannia University & 25 & 25 & 50 \\
\hline 3 & $\begin{array}{l}\text { Bangladesh Army International University of Science } \\
\text { and Technology (BAUST) }\end{array}$ & 25 & 25 & 50 \\
\hline 4 & CCN University of Science and Technology & 25 & 25 & 50 \\
\hline Total & & 100 & 100 & 200 \\
\hline
\end{tabular}

The above table shows the general information about the respondents. The total sample of our study was 200, where 50 percent of respondents were male students and the rest of 50 percent female students. Male-female as a sample (gender) was taken to determine the precise impacts of Social Networking Sites (SNSs) among the students.

\subsection{Age Group}

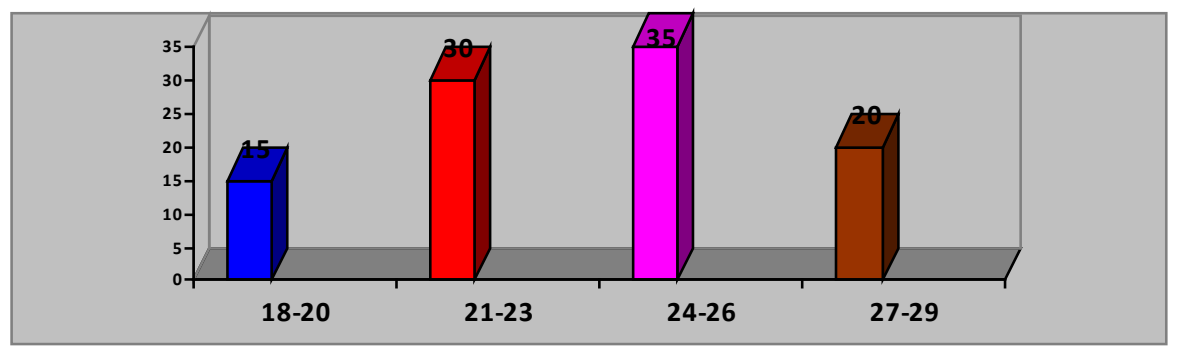

Figure 1. Age group and quantity of the respondents 
The above figure shows that the different age groups and their uses of SNSs. Maximum respondents (35\%) belong to the age group between $24-26$. We have identified that maximum students were in the third-year final semester or fourth-year first semester on these maximum age students. In the academic arena, this is the best time to build up a future career. However, maximum students waste their time just using or browsing SNSs. The second topmost respondents were 30 percent, and their age was between 21-23. The respondents argued that they were introduced to various SNSs and unconsciously enjoyed the exciting events of SNSs. The third topmost respondents were 20 percent, and their ages were between 27-29. The respondents were on the eve of completed their masters' courses. Students were mainly serious about their careers in this age group, therefore using SNSs scenarios was decreasing. We have also identified 15 percent of users and their ages between 18-20. The using level was lower only because of a newcomer in universities. The students were not familiar with all the SNSs. Just for this reason, the ratio was lower than others.

\subsection{Frequency of the Uses of SNS}

Table 2. Frequency of uses of SNSs

\begin{tabular}{|c|c|c|c|c|c|c|c|}
\hline $\begin{array}{l}\text { Preferences of uses of } \\
\text { SNSs }\end{array}$ & $\begin{array}{l}\text { Less than } 1 \\
\text { hour }\end{array}$ & 1-2 hours & 3-4 hours & 4-5 hours & $\begin{array}{l}\text { More than } \\
\text { hours }\end{array}$ & 6 & Total \\
\hline Facebook & 5 & 15 & 30 & 27 & 7 & & 84 \\
\hline Twitter & 2 & 8 & 11 & 10 & 1 & & 32 \\
\hline Viber & 1 & 8 & 12 & 9 & 1 & & 31 \\
\hline Imo & 0 & 6 & 10 & 9 & 0 & & 25 \\
\hline WhatsApp & 1 & 7 & 9 & 5 & 0 & & 22 \\
\hline Others & 1 & 2 & 3 & 0 & 0 & & 6 \\
\hline Total & 10 & 48 & 75 & 60 & 9 & & 200 \\
\hline
\end{tabular}

In our study, we have found that the using frequency of the SNSs. We have identified the maximum number of students using Facebook rather than other networking sites. Their number was eighty-four - the users using Facebook in different frequencies. We have found maximum (30) respondents using Facebook on an average of 3-4 hours in a day, and 27 respondents were using Facebook regularly in 4-5 hours. Seven respondents argued that they used Facebook more than 6 hours a day. We have also identified that five respondents use Facebook less than one hour a day, and 15 respondents use Facebook on an average of 1-2 hours a day. 
On the other hand, we have found that the second highest using social sites network is Twitter, and the user number was 32. The maximum number of Twitter users was 11, and they use it on an average of 3-4 hours and the lowest time user was two. One respondent argued that he had used Twitter for more than 6 hours, and the rest were different time users. The third topmost thirty-one uses the Viber. The maximum number of Viber users was 12, and they use the Viber on an average of 3-4 hours a day. The second most users of Viber were nine, and their using hours were between 4-5. We have found that one user uses Viber for more than 6 hours and one was less than one hour, and the rest of the eight respondents were using Viber 1-2 hours a day. The fourth highest user use Imo, and the number was 25 . The maximum number of Imo users was ten, and they use Imo for 3-4 hours a day. Nine respondents said that they use Imo 4-5 hours in a day, and six respondents said that they use 1-2 hours in a day. We have also found that twenty-two users use WhatsApp. Maximum Nine respondents use WhatsApp in 3-4 hours a day, and the lowest one respondent uses WhatsApp for less than one hour. Second, most users were seven and use WhatsApp 1-2 hours a day. Five user uses WhatsApp in 4-5 hours in a day. In this study, we have also identified six other respondents who have used other sites like YouTube, Line, Linked In, Myspace, etc. Only three respondents spent the maximum time (3-4 hours), and the minimum time user was one.

Finally, the result showed that a maximum of seventy-five respondents use SNSs in 3-4 hours a day, and sixty respondents regularly spent 4-5 hours. Minimum nine respondents spent the maximum time (more than 6 hours) using SNSs daily. We have identified forty-eight respondents who must use the SNSs on an average of 1-2 hours regularly in a day. Only ten respondents answered that they have use SNSs less than one hour a day regularly.

\subsection{Tenure of Uses of Social Networking Sites (SNSS)}

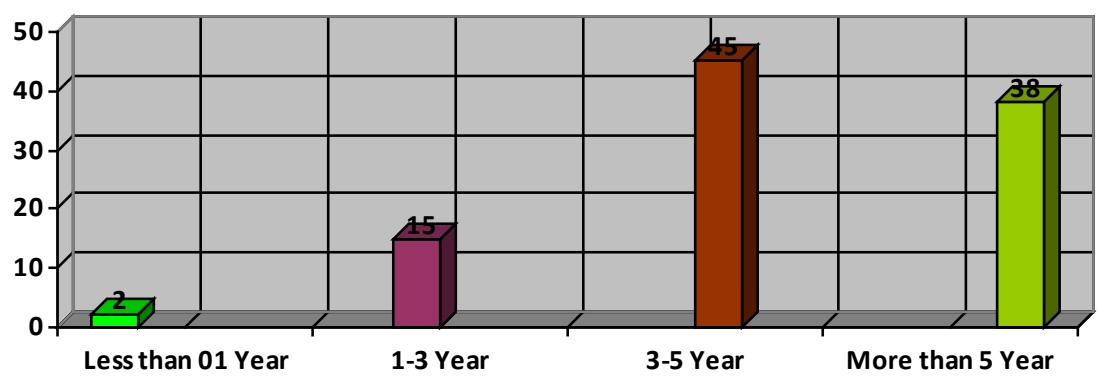

Figure 2. Tenure of uses SNSs

The above figure shows that the using tenure of SNSs of the respondents. The maximum user (45\%) uses the SNSs from 3-5 years, and thirty-eight percent of respondents answer that they must use SNSs for more than five years. Fifteen percent of respondents answered that they must 
use SNSs in 1-3 years. Very few respondents (2\%) argued that they just started using the SNSs less than one year. The students who have come from rural areas were not fond of the SNSs accurately. That is why we have identified some respondents who have started the use of SNSs. On the other side, the students from the urban area have used the SNSs from their school or college life.

\section{5 level of Interest in Using Social Networking Sites}

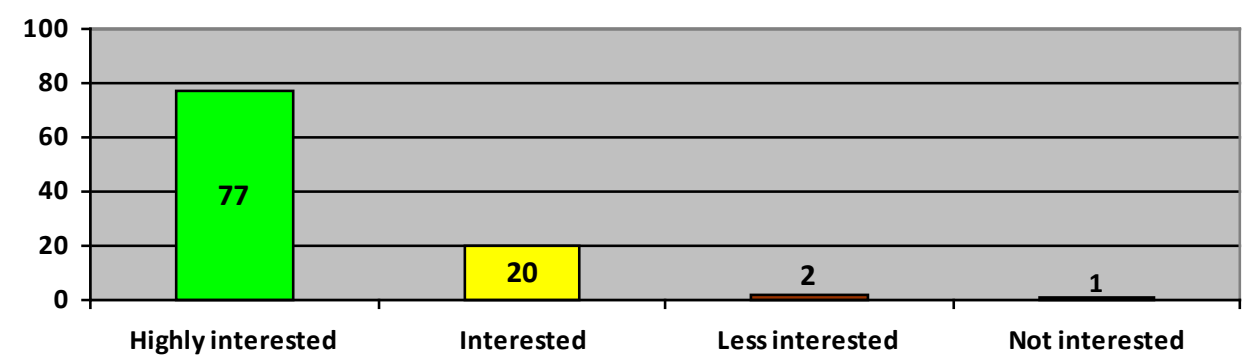

Figure 3. Level of interest in using SNSs

The above figure shows that the degree of interest in using SNSs of students. In this study, we found that 77 percent of respondents felt a high interest in using SNSs. Twenty percent of respondents replied that they felt moderately interest in using the SNSs. Only 2 percent of respondents felt less interest in using SNSs. However, 1 percent of respondents did not feel any interest in the SNSs.

\section{Access Device of Social Network Sites}

$\square$ PC $\square$ Laptop $\square$ Smartphone $\square$ I-pod/I-pad $\square$ Others

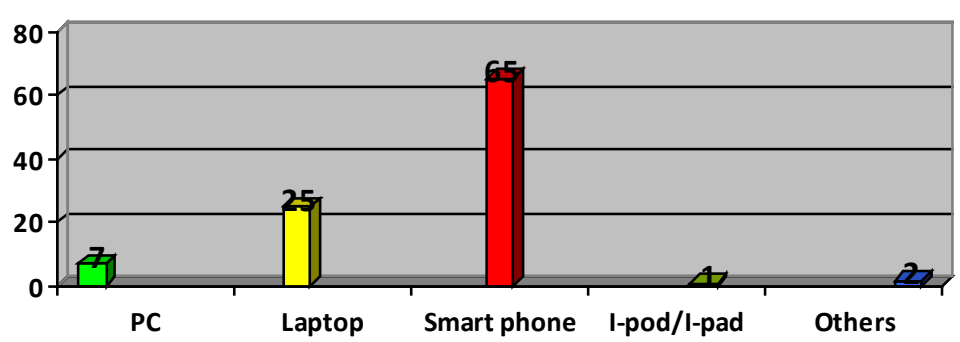

Figure 4. Level of the access device of SNSs

The above figure shows the scenario of the access device. We have found that a maximum of students $(65 \%)$ use SNSs by smartphone. For this, they use various types of smartphones. 
Twenty-five percent of respondents answered that they have use laptops for browsing SNSs. Seven percent of respondents use PC for SNSs purposes. Only 1 percent of respondents use I-pod/I-pad for using SNSs. Two percent of respondents use SNSs on different devices rather than the mentioned device.

\subsection{Preferred Time for Using Social Networking Sites}

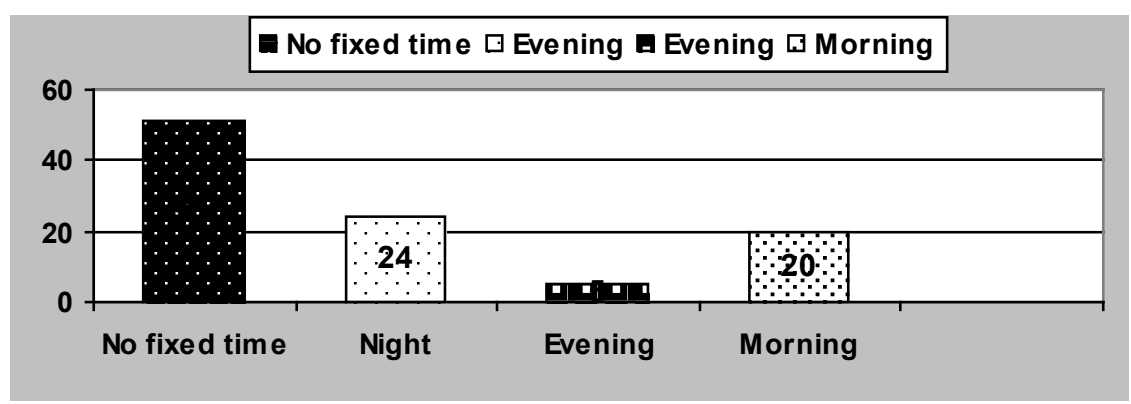

Figure 5. Preferred time of using of SNSs

The above figure represents the using preferred time in a day. Fifty-one percent of respondents said that there was no fixed time for using the SNSs in a day. Whenever they felt interested, they could use the SNSs. Twenty-four percent of respondents argued that they use SNSs at night because the company provide special offers to internet users at night. Twenty percent of respondents said they had used the SNSs in the morning because they have used the special internet offer. Internet providers provide special offers to the uses from night to morning. Only 5 percent of respondents use SNSs in the evening.

\subsection{Purpose of Using Social Networking Sites}

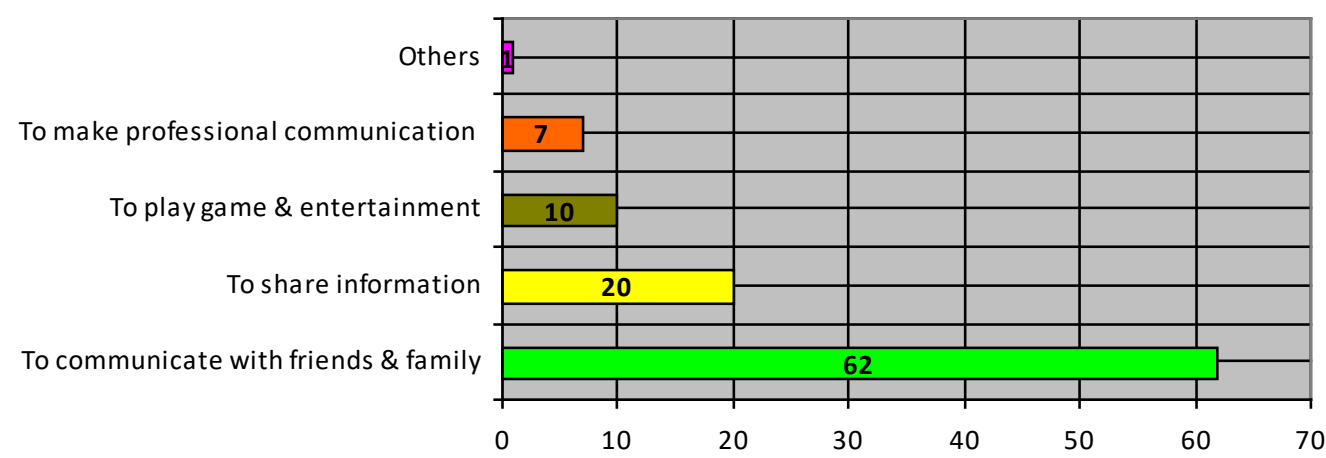

Figure 6. Purposes of using SNSs 
The SNSs are considered to share important links, information, and resources that help socially connect with their peers, friends, family, etc. The above figure shows that the using purposes of SNSs. Maximum students $(62 \%)$ use SNSs to communicate with friends and family. The respondents argued that it is the easiest way to communicate with their friends and family. Twenty percent of respondents said that they use SNSs for academic purposes by sharing important information and documents; 10 percent of respondents replied that they use the SNSs to play online games and watch different videos as entertainment. Seven percent of respondents argued that they use SNSs only for professional purposes. The respondents engaged with online business and part-time jobs. That is why online communication is essential to continue its purposes. Another 1 percent of respondents said that they have not any specific purpose for using the SNSs.

\subsection{Gender Basis Use of Social Networking Sites}

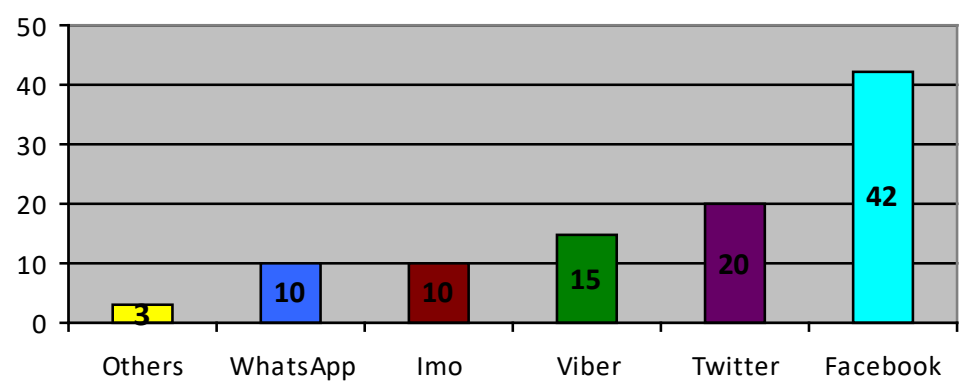

Figure 7. Frequency of gender basis use of SNSs

\section{Perception from male students}

The above figure shows the using frequencies of SNSs of male students. This study found that the maximum number of students $(42 \%)$ use Facebook, the most popular site. The second-largest respondents $(20 \%)$ use Twitter. On the other hand, the lowest levels of using sites were WhatsApp and Imo, and the respondents were 10 percent. Besides these, the other respondents (3\%) were also using some other sites like Line, Skype, Linked In, YouTube etc. 


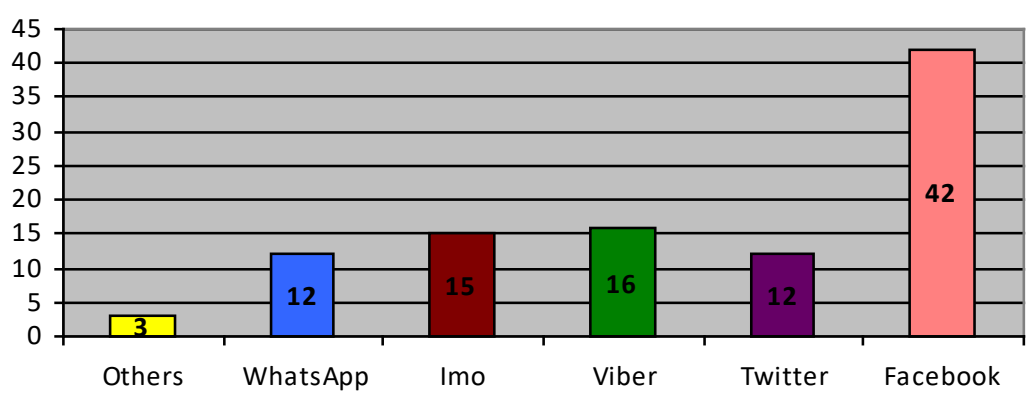

Perception from female students

The above figure shows the using frequencies of SNSs of female students. We also found that the maximum number of students (42\%) use Facebook rather than other sites. Sixteen percent of respondents use Viber to maintain communication with friends and family. Fifteen percent of respondents use Imo, and 12 percent used WhatsApp and Twitter to connect. The rest of the respondents (3\%) used other sites like Line, Skype, Linked In, YouTube etc.

\subsection{Scenario of Interpersonal Relationships with Family and Friends}

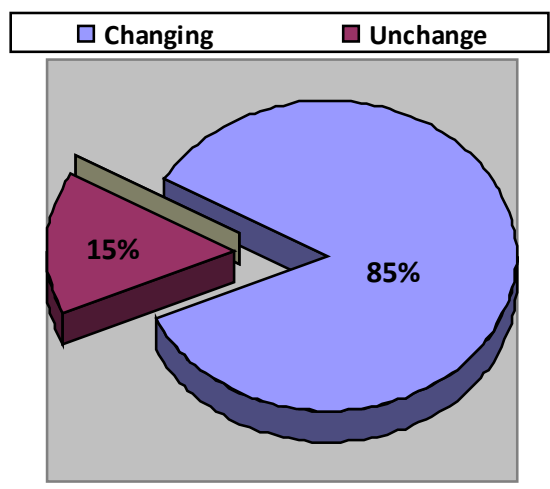

Figure 8. Effects of SNSs on interpersonal relationship

The above figure shows that the interpersonal relationship status after the use of SNSs. Excessive dependencies on the SNSs create various problems to continue the relationship with the relatives. After the habituation and use of SNSs maximum students (85\%) did not feel the interest to follow the existing norms, values, and cultures. That is why the interpersonal relationship scenario is changing day by day. On the other hand, 15 percent of respondents argued that SNSs would not create any problem maintaining their interpersonal relationships. However, the important aspect is that the respondents were not using social networking sites regularly. 


\subsection{Effects or Disadvantages of Social Networking Sites}

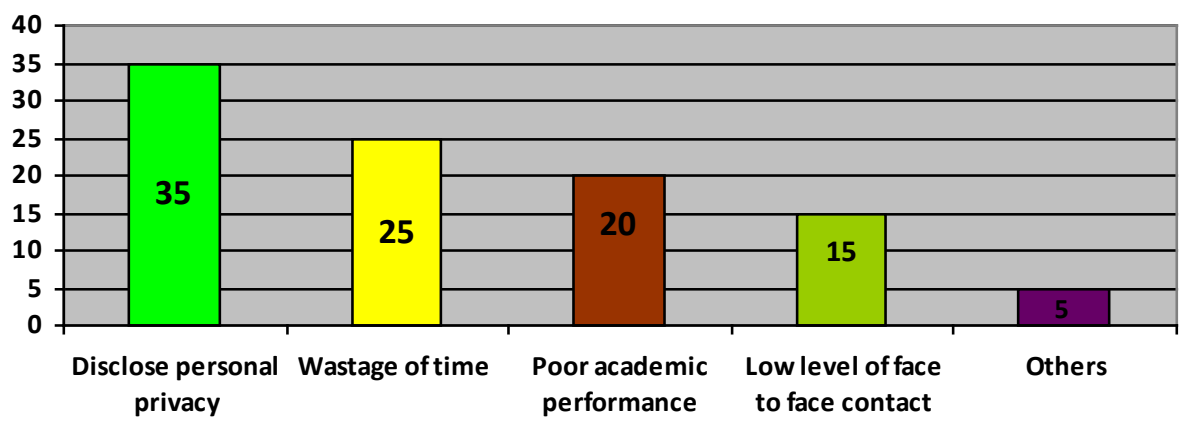

Figure 9. Effects of SNSs

The above figure shows that the effects of using SNSs. The extreme level of social networking sites creates lots of problems both in personal and family life. The majority of respondents (35\%) argued that their personal and family information (News, pictures) was available on their SNSs wall. Any visitor (either friends or unknown) can easily access the sites and get important information that may be harmful to personal or family life. On the other hand, our study shows that 25 percent of students use SNSs excessively. The extreme dependency hampers their daily activities and, for this reason, hardly completed their task in time. Extreme uses of SNSs are the cause of poor academic performance. Twenty percent argued that academic activities were directly or indirectly hampered using SNSs. More dependency creates a lower academic performance for the students. The dependency on SNSs also hampers social life. We have identified that 15 percent of respondents continue their communication with nears and dears by virtual sites instead of face-to-face communication. Five percent of respondents argued that they were almost isolated from others personally and socially. They were created virtual groups or members of a virtual world and were not found any interest in practical life.

\section{Discussion of Findings}

Young students are the most frequent users of social network sites (SNSs) in Bangladesh and all over the world. All the studies regarding social networking sites found that the students spent a considerable part of their life interacting with their near and dears through social media. Users may use social networks to communicate via local or social limits and share user-generated content such as photos and videos and play social games. According to the studies, the young generation is the primary user, and SNS dramatically influences their lives (Tankovska, 2021). On an average, users aged between 15 to 25 , spend on social media at least three hours a day. Our study found that almost all students were using the SNSs, which was relatively higher than the rate $(72 \%)$ of Irish teenagers (Machold et al., 2012). This rise can be explained by the fact that increasing numbers of students now access the internet through smartphones. 
With the invention of the newest technologies, smartphones are primarily due to their mobility as the chosen device for SNSs use. The advent of the selfie system of smartphones increased the general insanity. During this analysis, we found that all SNSs users have access via their smartphones. In this research, most respondents visit SNSs at least once a day, whereas maximum respondents visited the social sites more than five times a day. Furthermore, some users reported logging into their profiles more frequently all day than those who have less access (Madden et al., 2013). Maximum respondents felt that their academic activities and performance were seriously affected by the SNSs and afraid of their future careers. The frequent users' academic performance was not satisfactory, unlike the students who were not regular SNSs users. A survey of university students in Oman showed that approximately 36 percent thought they had distracted and impacted their study times by wasting their time on SNSs (Mehmood, 2013).

\section{Recommendations}

Though there are some positive sides to SNSs but many harmful effects of using social networking sites, it is challenging to control. Students spent valuable time in their life with SNSs. Only self-realization or awareness-building program may be the solution to control the more dependencies on SNSs. In this regard, we have made some recommendations which may help the students to concentrate on their study and will be helpful to reduce more use of SNSs:

$>$ The authority may regularly arrange career development counseling programs where discussing the harmful effects of excessive use of SNSs.

$>$ The government may take initiative, to involve more active participation of young generation in various social programs in family/ society.

$>$ To reduce excessive dependencies on SNSs, students need to be selective and shall try to use and adjust them schedule-wise.

$>$ Students must try to use their watch or mobile phone to set up a timer to limit their tenure on social networking sites.

$>$ Try to communicate with friends and family members physically, not through the virtual platform. Physical communication enriches the bondage stronger (Masthi et al., 2017).

\section{Conclusion}

The students are more conscious about the internet. The findings revealed that the attitudes of students regarding SNSs were varies based on gender. The internet provides us plenty of facilities with different dimensions. It helps our daily life be more accessible than before, and the usage rate of the internet increases daily. Students should take the internet positively. SNSs open the door to acquiring knowledge with a minimum investment of time and money. However, maximum students are unaware of the positive aspects of SNSs, which destroyed their valuable time in their life. So, they should take it as a part of their acquiring information from the entire world (Al \& Corresponding, 2011). The objective of our research was to examine the effects of 
the use of SNSs on students. This study also tried to explore how SNSs affect the lives and behaviors of students. Importantly, social networking sites are top-rated sites among young peoples, and most of them are active members and users of SNSs. However, from the perspective of university students, it is not too important to spend more time on it. They should spend their valuable time, which will not hamper their academic, personal, and social life. So, students need to more careful about the use of SNSs. On the other hand, family members and university authorities should give more attention to the young generation, especially the students.

\section{References}

Al, A., \& Corresponding, M. (2011). Students' Attitudes towards Internet: A study on Private Universities of Bangladesh. European Journal of Business and Management, 3(6).

Aliyas P. J., et al. (2012). The Effect of Social Networking Sites on Students in India. Journal of Human Behavior and Computer, 28, 21.

Bristy, J. F. (2016). Jannatul Ferdous Bristy. The Journal of social media in Society, 5(1), 137-159. Retrieved from http://thejsms.org/index.php/TSMRI/article/view/128/68

Editor. (2013). 33 million Internet users in Bangladesh. Dhaka Mirror Online News Portal.

Tankovska, H. (2021). Social media - Statistics \& Facts. Statista.Com. https://www.statista.com/topics/1164/social-networks/

Himel, S. U. (n.d.). Social Media and its impact on Bangladesh. 1-16.

HM, B. (2017). Social Networking Experiences on Facebook: A Study on the Stude nts' of Comilla University. Journal of Mass Communication \& Journalism, 07(03), 3-8. https://doi.org/10.4172/2165-7912.1000333

Hosain Shahid Shohrowardhy, H. K. (2012). Students' perception of social networking for academic purposes in Bangladesh $M \& M$.

M. Aminuzzaman Saluddin. (n.d.). Introduction to Social Research.

Machold, C., Judge, G., Mavrinac, A., Elliott, J., Murphy, A. M., \& Roche, E. (2012). Social networking patterns/hazards among Irish teenagers. Irish Medical Journal, 105(5).

Madden, M., Lenhart, A., Cortesi, S., Smith, A., \& Beaton, M. (2013). Teens, Social Media, and Privacy.

Masthi, N. R. R., Pruthvi, S., \& Mallekavu, P. (2017). a Comparative Study on Social Media Addiction Between Public and Private High School Students of Urban Bengaluru, India. ASEAN Journal of Psychiatry, 18(2), 0-0.

Meena, P. S., Mittal, P., Durlabhji, S., Hospital, M., \& Solanki, R. K. (2012). Problematic use of social networking sites among urban school-going teenagers. Industrial Psychiatry Journal, July. https://doi.org/10.4103/0972-6748.119589

Mehmood, S. (2013). The Effects of Social Networking Sites on the Academic Performance of Students in College of Applied Sciences, Nizwa, Oman. 2(1), 111-125. 
Sultana, S. (2017). Social Networking Sites (SNS) and Family Relationship: A Study on Youths of Dhaka City. IOSR Journal of Humanities and Social Science, 22(04), 46-52. https://doi.org/10.9790/0837-2204024652

\section{Copyrights}

Copyright for this article is retained by the author(s), with first publication rights granted to the journal.

This is an open-access article distributed under the terms and conditions of the Creative Commons Attribution license (http://creativecommons.org/licenses/by/4.0/) 